\title{
Sistem Pengelolaan Dan Pendistribusian Wakaf Tunai Pada Lembaga Nirlaba
}

\author{
(Studi Kasus Pada Yayasan Yatim Mandiri) \\ Nuraliyah Rasyidah Hasyim \\ UIN Alauddin Makassar \\ nuraliyahrasidah97@gmail.com
}

\begin{abstract}
Abstrak:
Tujuan dari untuk mengetahui bagaimana sistem pengelolaan dan pendistribusian wakaf tunai pada lembaga nirlaba. Dalam Penelitian ini, peneliti menggunakan pendekatan kualitatif. data yang digunakan dalam penelitian ini menggunakan data primer dan data sekundner yaitu wawancara, observasi dan dokumentasi. Hasil dari penelitian ini menunjukkan bahwa Yayasan Yatim Mandiri Makassar memliki dua program, diantaranya ialah wakaf pembangunan dan wakaf al quran. Yayasan Yatim Mandiri Makassar juga memberikan sertifikat wakafuang kepada wakif pada batasan tertentu dari jumlah uang yang diwakafkan setelah wakif mengutarakan niatnya dan menyerahkan sejumlah uang yang dimaksud. Dalam penghimpunan wakaf uang pada yayasan yatim mandiri, strategi fundraising yang digunakan oleh fundreiser (zisco) yayasan yatim mandiri meliputi, direc dan strategi indirec fundraising dengan metode above the line. Pendistribusian wakaf serta pemanfaatannya melalui beberapa langkah yang teliti.

Kata Kunci : Wakaf Tunai, Pengelolaan, Pendistribusian
\end{abstract}

\section{PENDAHULUAN}

Di Indonesia, wakaf telah dikenal dan dilaksanakan oleh umat Islam sejak agama Islam masuk di Indonesia. Sebagai suatu instrumen islam, wakaf telah menjadi salah satu penunjang perkembangan masyarakat islam. Sebagian besar tanah wakaf di indonesia digunakan untuk rumah ibadah, perguruan tinggi islam dan lembaga - lembaga keagamaan Islam lainnya. Wakaf di Indonesia saat ini 
diatur dalam Undang - Undang Nomor 41 tahun 2004 tentang perwakafan. Undang -Undang ini selain menyempurnakan peraturan perwakafan yang telah ada, juga mengatur masalah - masalah baru, seperti pengelolaan harta benda wakaf harus secara produktif dan peruntukkannya dirinci secara jelas, diantaranya untuk membantu fakir miskin, pembentukan badan wakaf Indonesia, pengaturan wakaf uang, dan materi - materi lainnya yang dibutuhkan sesuai perkembangan kontemporer. $^{1}$

Dengan persoalan yang semakin kompleks, maka lahirlah model wakaf baru yaitu wakaf tunai. wakaf tunai merupakan dana yang dihimpun oleh pengelola wakaf (Nazhir) melalui penerbitan sertifikat wakaf tunai yang dibeli masyarakat. Wakaf tunai dapat juga diartikan mewakafkan harta berupa uang atau surat berharga yang dikelola oleh institusi (perbankan atau lembaga keuangan syari'ah) yang keuntungannya akan disedekahkan, dengan syarat modalnya tidak bisa dikurangi untuk sedekahnya, sedangkan dana wakaf yang terkumpul selanjutnya dapat digulirkan dan diinvstasikan oleh nadzir ke dalam berbagai sektor usaha yang halal dan produktif, sehingga keuntunganya dapat dimanfaatkan untuk pembangunan umat dan bangsa secara keseluruhan. ${ }^{2}$

Kalangan ulama fikih masih kerap kali memperdebatkan apa hukumnya mewakafkan uang tunai. Ada yang membolehkan dan ada pula yang tidak membolehkan berwakaf dengan uang tunai. Hal ini disebabkan oleh cara yang biasa dipakai oleh masyarakat dalam mengembangkan harta wakaf berkisar hanya pada penyewaan harta wakaf, seperti tanah, gedung, rumah dan sejenisnya. Diantara alasan beberapa ulama tidak membolehkan berwakaf uang, yaitu: ${ }^{3}$

a. Uang bisa habis zatnya dalam sekali pakai. Uang hanya dimanfaatkan dengan membelanjakannya, sehingga bendanya lenyap. Padahal inti dari

\footnotetext{
${ }^{1}$ Muhammad Isadur Rofiq, studi analisis tentang peran nadzir dalam pengelolaan tanah wakaf ditinjau dari perspektif UU Nomor 41 tahun 2004 pasal 11 (studi kasus di desa Dombo Kec. Sayung Kab. Demak), skripsi, hal 4

${ }^{2}$ Asep Suganda, Konsep Wakaf Tunai islamic economic, Jurnal Ekonomi Islam, 2014 hal

${ }^{3}$ Asep Suganda, Konsep Wakaf Tunai islamic economic, Jurnal Ekonomi Islam, 2014 hal

7
} 
ajaran wakaf adalah pada kesenimambungan hasil dari modal dasar yang tetap dan kekal. Oleh karena itu, ada persyaratan agar benda yang akan diwakafkan itu adalah benda yang tahan lama, tidak habis dipakai.

b. Uang seperti dirham dan dinar diciptakan sebagai alat ukur yang mudah, orang melakukan transaksi jual beli, bukan untuk ditarik manfaatnya dengan mempersewakan zatnya,

Saat ini, indonesia masih mengalami kesulitan wakaf tunai atau uang untuk meningkatkan kesejahteraan masyarakat. Karena masyarakat Indonesia yang mayoritas muslim ini belum terbiasa dengan wakaf uang. Padahal wakaf tunai dapat meningkatkan kesejahteraan masyarakat. Siti Muflichah, SH MH, saat ujian terbuka untuk mearih gelar doktor di Fakultas Hukum Universitas mengungkapkan pelaksanaan pengelolaan wakaf tunai di Indonesia banyak menemui persoalan. Hal ini disebabkan masih banyak masyarakat terhadap nadzir membuat tanah wakaf tidak dimanfaatkan untuk meningkatkan kesejahteraan kaum miskin. ${ }^{4}$

Wakaf dengan menggunakan uang tunai membuka peluang yang unik bagi penciptaan investasi di bidang keagamaan, pendidikan, serta kegiatan sosial. Masyarakat yang berpenghasilan tinggi dapat dimanfaatkan melalui penukaran sertifikat wakaf tunai, sedangkan pendapatan yang diperoleh dari pengelolaan wakaf tunai tersebut dapat digunakan untuk berbagai kepentingan kemaslahatan umat. Salah satunya, alokasi wakaf tunai dapat dialihkan pada benda seperti alqur'an demi kemajuan agama.

Banyaknya masyarakat muslim yang ingin berdonasi, namun tidak memiliki aset produktif seperti tanah, menjadikan program wakaf tunai menjadi solusi alternatif bagi masyarakat. Namun, aspek kemudahan ini harus direspon dan dikelola dengan baik oleh para pengelola dana wakaf agar dapat tersalurkan dengan baik dan menunjang optimalisasi pendayagunaan dana wakaf untuk kemashlatan umat.

\footnotetext{
${ }^{4}$ https://www.jogpaper.com/index.php/disertasi/202-indonesia-masih-kesulitan-terapkanwakaf-tunai
} 


\section{TINJAUAN PUSTAKA}

\section{Pengertian wakaf}

Secara bahasa kata wakaf (al-waqf) berarti al-habs yang secara bahasa Indonesia dirtikan menahan. Hal ini sebagaimana perkataan seseorang waqafayaqifu-waqfan, artinya habasa-yahbisu-habsan. Kata al-waqfu bila dijamakkan menjadi al-awqaf dan wuquf, sedaangkan bentuk kerjanya (fi'il) adalah waqafa. Menurut bhasa, waqafa berarti menahan atau mencegah, misalnya kata waqaftu 'ani al-sairi, yang bermakna "saya menahan diri dari berjalan". Dalam peristilahan syara', wakaf adlah sejenis pemberin yang pelaksanaannya dilakukan dengan jalan menahan (pemilikan) asal (tahbisu al-ashli), lalu menjadikan manfaatnya berlaaku umum. 5

Dalam bahasa hukum kontemporer, wakaf berarti pemberian, dilakukan atas kehendak ahli waris, dengan satu niat memenuhi panggilan ketaqwaan. Wakaf juga dapat diartikan sebagai harta yang disumbangkan untuk berbagai tujuan kemanusiaan, sekali dalam selamanya, atau penyerahan aset tetap oleh seorang sebagai bentuk manifestassi kepatuhan terhadap agama.

Adapun secara terminologi, terdapat beberapa pengertian yang di kemukakan oleh ulama diantaranya adalah Menurut Sayyid Sabiq, wakaf adalah menahan harta dan menggunakana manfaatnya di jalan Allah swt. Sedangkan menurut Menurut Syaikh Abu Bakar Jabir al-Jazaeeiri, wakaf adalah penahanan suatu harta sehingga harta itu tidak dapat diwariskan, dijual atau dihabiskan dan hasilnya diberikan kepada penerimanya. ${ }^{6}$

Pengertian lainnya dapat ditemui dalam Undang - Undang Nomor 41 tahun 2004, bahwa wakaf artinya suatu perbuatan hukum wakif untuk memisahkan dan/atau menyerahkan sebagiaan harta benda miliknya untuk dimanfaatkan

\footnotetext{
${ }^{5}$ Muhammad Aziz, 'Peran Badan Wakaf Indonesia (BWI) Dalam Mengembangkan Prospek Wakaf Uang Di Indonesia', JES (Jurnal Ekonomi Syariah), 2.1 (2017), 35-54 <https://doi.org/10.30736/jesa.v2i1.14>.

${ }^{6}$ Sirajuddin Sirajuddin and Asrum Yolleng, 'PEMBERDAYAAN TANAH WAKAF SEBAGAI POTENSI EKONOMI UMAT DI MASJID AL-MARKAZ AI-ISLAMI MAKASSAR', LAA MAISYIR : Jurnal Ekonomi Islam, 5.1 (2018), 80-106.
} 
selamanya atau untuk jangka waktu tertentu sesuai dengan kepentingannya guna keperluan ibadah dan/ atau kesejahteraan umum menurut syariah. ${ }^{7}$

Wakaf adalah tanah negara yang tidak dapat diserahkan kepada siapapun dan digunakan untuk tujuan amal; benda bergerak atau tidak bergerak yang disediakan untuk kepentingan umum (islam) sebagai pemberian yang ikhlas; hadiah atau pemberian yang suci. Maka, wakaf adalah menhan harta wakaf dari si pemberi harta wakaf (waqif) untuk kesejahteraan si penerima manfaat harta wakaf (mauquf 'alaih) yang dikelola oleh organisasi wakaf (nazhir). ${ }^{8}$

Dari beberapa definis wakaf yang telah dipaparkan diatas, dapat disimpulkan bahwa wakaf bertujuan untuk memberikan manfaat atau faedah harta yang diwakafkan kepada orang yang berhak dan digunakan sesuai dengan ajaran syariah islam. Dapat dikatakan juga bahwa wakaf sebagai sesuatu yang substansi (wujud aktiva) dipertahankan, sementara hasil atau manfaatnya digunakan sesuai dengan keinginan dari orang yang menyerahkan (waqif) dengan proses legal sesuai dengaan fungsi wakaf yang disebutkan dalam UU No. 41 tahun 2004 pasal 5 yang menyatakan wakaf berfungsi untuk mwujudkan potensi dan manfaat ekonomis harta benda wakaf untuk kepentingan ibadah dan untuk memajukan kesejahteraan umum. ${ }^{9}$

\section{Pengertian Wakaf Tunai}

Dalam melakukan wakaf tunai, ada cara yang harus diperhatikan. Menurut madzab Hanafi, hal yang perlu diperhatikan dalam wakaf tunai adaalah dengan menjadikannya modal usaha dengan cara mudharabah atau mubadha'ah. Sedangkan keuntungannya disedekahkan kepada pihak wakaf. Ibnu Abidin mengemukakan bahwa wakaf tunai yang dikatakan merupakan kebiasaan yang berlaku dimasyarakat adalah kebiasaan yang berlaku dimasyarakat adalah kebiasaan yang berlaku di wilayah Romawi, sedangkan di negara lain wakaf tuai

\footnotetext{
${ }^{7}$ Undang - Undang RI No. 41 Tahun 2004 tentang wakaf, Departemen Agama RI, Dirjen Bimas Islam dan Penyelenggaraan Haji, 2005, hal 3

${ }^{8}$ Sayidatu Syarifah Sudrajat, efekivitas pendayagunaan dana wakaf terhadap programprograam Badan Wakaf Al-Qur'an Jakarta, UIN Syarif Hidayatullah,2016, hal 17

${ }^{9}$ Asep Suganda, Konsep wakaf tunai, jurnal ekonomi islam,2015, hal 3
} 
bukan merupakan kebiasaan. Oleh karena itu, Ibnu Abidin berpandangan bahwa wakaf tunai tidak boleh atau tidak sah. Yang juga berpandangan bahwa wakaf tunai tidak boleh dalam madzhaab Syafi'i, menurut al-Bakri, Madzhab Syafi'i tidak membolehkan wakaf tunai, karena uang (dahulu berupa dinar dan dirham) akan lenyap ketika dibayar sehingga tidak ada lagi wujudnya. Pada hakikatnya, perbedaan boleh tidaknya wakaf tuni berkisar pada wujud uang. ${ }^{10}$

Dilihat dari pengertiannya wakaf tunai merupakan dana atau uang (seperti infaq) yang dihimpun oleh institusi pengelola wakaf (nadzir) melalui penerbitan Sertifikat Wakaf Tunai (SWT) yang dibeli oleh masyarakat. Dalam hal ini wakaf tunia dapat juga diartikan mewakafkan atau menginfakkan hara berupa uang atau surat berharga yang dikelola oleh institusi perbankkan atau lembaga keuangan syariah yang keuntungannya akan disalurkan kepada pihak yang membutuhkan, tetapi modalnya (ashlnya) tidak bisa dikurangi untuk disalurkan, sedangkan dana wakaf yang terkumpul slanjutnya dapat digulirkan dan diinvestasikan oleh pengelola wakaf ke dalam berbagai lembaga - lembaga usaha yang halal dan produktif. Imam al-Zuhri juga mengemukakan pendapat yang senada, yaitu menegaskan bahwa mewakafkan dinar hukumnya bileh, dengan cara menjadikan dinar tersebut sebagai modal usaha kemudian keuntungannya disalurkan atau disedekahkan kepada orang/ sesuatu yang menjadi mauquf 'alaih (tujuan wakaf).

Dilihat dari segi ekonomi, wakaf tunai sangat potensial untuk dikembangkan di Indonesia, karena dengan model wakaf ini daya jangkau mobilisasinya akan jauh lebih merata kepada sebagian masyarakat dibandingkan dengan model wakaf - wakaf tradisional -konvensional, yaitu dalam bentuk harta fisik yang biasanya dilakukan oleh keluarga yang terbilang relatif lebih mampu.

\section{Sejarah Wakaf Tunai}

Perilaku sejenis wakaf telah dikenal umat manusia seelum Islam datang. Umat manusia (terlepas dari agama dan kepercayaan yang mereka anut) sesungguhnya

\footnotetext{
${ }^{10}$ Ahmad Atabik, 'Manajemen Pengelolaan Wakaf Tunai Di Indonesia', Ziswaf, 1.1
} (2014), 82-107. 
telah mengenal beberapa bentuk praktik pendayagunaan harta benda, yang subtansinya tidak jauh berbeda dengan wakaf dalam islam. Hal ini disebabkan pada dasarnya, umat manusia sudah menyembah Tuhan melalui rituaal keagamaan sesuai kepercayaan mereka. Hal inilah yang kemudian menjadi faktor pendorong bagi setiap umat beragama untuk mendirikan bangunan peribadaatannya masing masing. Contoh yang paling nyata dari adanya praktik wakf sebelum islam adalah dibangunnya al- Ka'bah al Musyarrafah oleh Nabi Ibrahim AlaihiSaalam. Hanya saja, dalam perjalanan waktu, Ka'bah pernah digunakan sebagai tempat penyembahan berhala, padahal sebelumnya adalah tempat beribadh kepada Allah SWT.

Jika praktik wakaf telah dikenal sebelum islam, maka yang membedakannya dengan wakaf dalam Islam adalah bahwa praktik wakaf yang diamalkan masyarakat jahiliyah dilakukan semata - mata hanya untuk mencari prestise (kebanggaan). Sedangkan dalam Islam bertujuan untuk mencari ridha Alah dan sebagai sarana mendekatkan diri kepada-Nya. ${ }^{11}$

Dalam sejarah Islam, wakaf dikenal sjak masa Rasulullah SAW karena wakaf disyariatkan pada tahun kedua hijriyah. Ada dua pendapat yang berkembang dikalagan ahli yurisprudensi Islam (fuqaha') tentang siapa yang pertama kali melaksanakan syariat wakaf. Menurut sebagian pendapat ulama mengatakan bahwa yang ppertama kali melaksanakan wakkaf adalah Rasulullah SAW yaitu wakaf tanah milik Nabi SAW untuk dibangun masjid. Sebagian ulama menyatakan bahwa yang pertama kali melaksanakan syariat wakaf adaalah Umar bin Khattab. Pendapat ini berdasarkan hadits yang diriwayatkan Ibnu Umar ra, sebagaiamana telah dikemukakan di atas.

Praktek wakaf juga berkembang luas pada masa dinasti Umayah dan Dinasti Abasiyah dan dinasti sesudahnya, banyak orang berduyun - duyun untuk melaksakan wakaf, dan wakaf tidak hanya untuk orang - orang fakir dan miskin saja tetapi wakaf. Menjadi modl untuk membangun lembaga pendidikan,

${ }^{11}$ Tho'in Muhammad and lin Emy Prastiwi, 'Wakaf Tunai Perspektif Syariah', Jurnal Ilmiah Ekonomi Islam, 01.01 (2015), 61-74. 
membangun perpustakaan dan membayar gaji para stafnya, gaji para guru dan beasiswa untuk para siswa dan mahsiswa. Antusiasme masyarakat kepada pelaksanaan wakaf telah menarik perhatian negara untu mengatur pengelolaan wakaf sebagai sktor untuk membangun solidaritas sosial dan eknomi masyarakat.

Wakaf tunai pertama kalidipakai pada masa Utsman di Mesir, diakhir abad ke 16 (1555 - 1823 M). Pada era Utsman di Mesir, berkembang pemakaian fikih Hanafi dalam menjalankan aktivitas bisnis dan sosialnya. Imam Muhammad asy-Syaibani menjelaskan bahwa sekalipun tidak ada dukungan hadis yang kuat, penggunaan harta bergerak sebagai wakaf dibolehkan, jika memang hal itu sudah menjaadi kebiasan umum pada daerah tertentu. Bahkan bagi Imam Muhammad al Sarrkhsi, kebiasaan umum tidak selalu menjadi persyaratan dalam penggunaan harta bergerak sebagai harta wakaf. Bahkan menurut Crecelius, dia menyatakan ${ }^{12}$ :

"No Islamic State was more energetic in its production of statiscal records, moresystematic in its record keeping, and more assiduous in preserving these records thanthe ottoman Empire"

Artinya : "tidak ada negara Islam yang lebih energik dalam menghasilkan wakaf dan catatan statistiknya, lebih sistematis dalam menjaga catatan tersebut, serta lebih ketat dalam mengawasi cattaan tersebut ketimbang Dinasti Utsman”

Terdapat tiga alasan mendasar kenapa ahli fiqh era Utsmani menyusun bangunan wakaf tunai : pertama, pandangan bahwa aset bergerak dapat menjadi harta wakaf. Kedua, penilaian dan penerimaan atas uang sebagai aset bergrak. Ketiga, persetujuan atas pemberian uang tunai.

Kepopuleran wakaf tunai terjadi setelah professor Mannan mensosialisasikannya di Bangladesh melalui social Investment Bank Limited (SIBL). SIBL membuat sertifikat wakaf tunai (cash Waqf certificcate) untuk mengumpulkan dana dari orang kaya dan membagi perolehan wakaf tunai yang telah dikumpulkannya kepada orang - orang miskin. Popularitas “wakf tunai', ditimbulkan karena fleksibilitas

\footnotetext{
12 Muhammad and Emy Prastiwi.
} 
penyebaran manfaat wakaf tunai kepada kalangan mustadh'afin (orang fakir dan orang yang tertindas ekonominya dan $d h u^{\prime} a f a$ ' (orang miskin) di segala tempat.

Pada era kemerdekaan Republik Indonesia pemerintahan Indonesia tetap memberlakukan peraturan wakaf Kolonial Belanda berdasarkan bunyi Pasal II aturan peralihan UUD 1945. Namun sejak terbentukkan kementrian Agama pada tanggal 3 Januari 1946, urusan tanah wakaf menjadi urusan kementrian Agama bagian D (Ibadah sosial). Untuk memberi kejelasan hukum wakaf lahir undang undang nomor 51960 tentang agraria yang sekaligus menguatkan eksisensi wakaf di Indoensiaa. Juga peraturan pemerintah nomor 28 tahun 1977 tentang perwakafan Tanah milik. Kemudian diperkuat lagi dengan Undang - Undang Nomor 7 tahun 1989 tentang peradilan agama yang menangani tentang sengketa tanah wakaf. Pada tahun 1991 presiden mengeluarkaan institusi nomor 1 tanggal 10 Juni tentang pedoman bagi instansi pemerintah dan masyarakat dalam menyelesaikan berbagai masalah hukum dibidang hukum perwakafan.

Yang pada endingnya, dengan melihat perkembangan situasu dan kondisi zaman yang telah melesat maju, dan sesuatu yang tidak dapat dihindarkan lagi entang pentingnya uang (bentuk kntan) dalam bertransaksi, maka kalangan ulama' Indonesia, dalam hal ini adalah MUI telah melihat pentingnya pengembangan pemikiran wakaf yang tidak terbatas pada wakaf benda mati saja, maka MUI merespon positif diperbolehkannya wakaf tunai ini. Pada tanggal 11 Mei 2002 MUI mengeluarkan fatwa tentang diperbolehkannya wakaf uang (waqf al- nuqud), dengan syarat nilai pokok wakaf dijamin kelestariannya dan dapat dimanfaatkan untuk waktu yang tidak terbatas baik kepentingan individu maupun golongan masyarakat. $^{13}$

\section{Pengelolaan Wakaf Tunai di Indonesia}

Pengelolaan dana wakaf tunai telah diatur dalam UU No. 41 tahun 2004 tentang Wakaf mnyebutkan bahwa wakif dapt mewakafkan benda bergerak berupa uang melalui lembaga keuangan syariah yang ditunjuk oleh menteri. Setelah wakif

\footnotetext{
${ }^{13}$ Atabik.
} 
menyerahkan wakaf uangnya kemudian LKS akan menerbitkan dan menyampaikan sertifikat wakaf uang kepada wakif dan nazhir sebagai bukti penyerahan harta benda waakaf.

Dalam sisem pengelolaan wakaf uang, nazhir bertugas untuk menginvestasikan sesuai dengan syariah, dengan satu syarat : nominal uang yang diinvestasikan dialokasikan untuk upah nazhir (maskimal 10\%) dan kesejahteraan masyarakat (minimal 90\%)

\section{METODE PENELITIAN}

Pada penelitian ini penulis menggunakan metode penelitian kualitatif, dengan cara turun langsung kelapangan untuk meneliti hal - hal yang menjadi pokok permasalahan tersebut. Dan adapun yang dimaksud dengan penelitian kualitatif adalah prosedur penelitian yang bersifat deskritif dan cenderung menggunakan analisis.

Disini penulis mendeskripsikan keadaan objek penelitian yang sesungguhnya untuk mengetahui dan menganalisa Yayasan Yatim Mandiri kota Makassar. Kemudian data yang digunakan dalam penelitian ini adalah data primer dan sekunder yang dikumpulkan oleh peneliti dan kemudian di analisis untuk memperoleh hasil dengan melahirkan sebuah kesimpulan.

\section{HASIL DAN PEMBAHASAN}

\section{Gambaran Umum Perusahaan}

Yatim mandiri merupakan lembaga nirlaba yang fokus pada upaya memandirikan anak yatim dan dhuafa melalui pengelolaan dana zakat, infaq, sedekah, wakaf dan lainnya. Berawal dari dari kegelisahan beberapa orang aktivis panti asuhan di Surabaya yaitu Sahid Has, Sumarno, Hasan Sadeli, Syarif Mukhodam dan Moch Hasyim yang melihat anak - anak yatimyang lulus SMA dipanti assuhan. Karena tidak semua panti Asuhan mampu untuk menyekelohkan para anak binaan sampai ke perguruan tinggi atau mampu mencarikan merekaa 
lapangan pekerjaan jadi sebagian besar anak - anak yatim ini dipulangkan kembali kepada orang tuanya yang masih ada. Setelah mereka pulang kembali maka hidup mereka akan kembali seperti semula. Melihat kondisi seperti ini, mereka berpikir bagaimana anak - anak ini bisa hidup mandiri tanpa tergantung lagi epada orang lain. $^{14}$

Kemudian mereka merancang sebuah Yayasan yang bergerak dalam pendidikan anak yatim purna asuh dari panti asuhan dengan program mengikutsertakan anak - anak yatim itu maka pada tanggal 31 Maret 1994 dibentuklah sebuah yayasan yang diberi nama Yayasan Pembinaan dan Pengembangan Panti Asuhan Islam dan Anak Purna Asuh (YP3IS). Kemudian tanggal tersebut dijadikan sebagai hari lahir

Dalam perjalanannya selama 14 tahun berbagai catatan perjalanan telah terhimpun. Baik yang berkaitan dengan legalitas maupun operasional kesehariannya. Diantara sesuai dengan undang - undang nomor 16 tahun 2000 tentang yayasan batas toleransi penyesuaiannya adalah tahun 2005, sehingga demi kpentingan public yaysan harus melakukan pendaftaran ke Depkumham pusat di Jakarta tenyata Depkumham menolak karena nama YP3IS telah digunakan oleh pihak lain. Catatan yang lain, nama YP3IS semakin berkembang dengan baik berkat dukungan dana dari masyarakat dan semakin profesional untuk memandirikan anak yatim melalui program - programnya. Setelah melalui banyak perubahan baik secara kepengurusan maupun secara manajemen dan untuk memperluas kemanfaatan memandirikan anak yatim maka melalui rapat, diputuskan untuk mengganti nama menjadi Yatim Mandiri. Pada tanggal 22 juli 2008 Yatim Mandiri terdaftar di Depkumham dengan nomor: AHU-2413.AH.01.02.2008. dengan nama baru Yatim Mandiri diharapkan akan menjadi lembaga pemberdaya anak yatim yang kuat di negeri inni. Sampai tahun 2014 ini saat Yatim Mandiri diharapkan akan menjadi lembaga pemberdaya anak yatim yang kuat di negeri ini. Sampai tahun 2014 ini saat usia Yatim Mandiri sudah memiliki 40 kantor Cabang di 12 Provinsi di Indonesia. Hal ini mencangkup beberaapa daerah kota besar, yakni saat

\footnotetext{
${ }^{14}$ https://www.yatimmandiri.org/welcome/profil
} 
ini Yayasan Yatim Mandiri telah hadir di 11 Jaringan kantor kota besar di Jawa Timur dan Jawa Tengah. Kota besar yang sudah terdapat kantor operasional Yayasan Yatim Mandiri antara lain, Surabaya, Sidoarjo, Gresik, Malang, Kediri, Jember, Tuban, Pasuruan, Semarang, Mojokerto, Makassar dan Madiun.

Untuk yatim mandiiri yang ada di Makassar sendiri berdiri pada tahun 2011, dan sudah beroperasi kurang lebih sembilan tahun yang memiliki kantor beralamatkan di Jl. Andi Tonro Makassar. Dengan berbagai program kemandirian yang ada, harapannya Yatim Mandiri di seluruh Indonesia semakin berkembang lebih baik dan mampu menebar manfaat lebih luas.

\section{Pengelolaan dan pendistribusian Yayasan Yatim Mandiri}

Secara umum, program wakaf di Yayasan Yatim Mandiri Makassar terbagi dua yaitu wakaf pembangunan dan wakaf al quran. Wakaf pembangunan disini berupa pembangunan Sekolah Tinggi Agama Islam An- Najah Indonesia Mandiri (STAINIM) yang bertempat di Sidoarjo. STAINIM ini merupakan perguruan tinggi resmi yang dimiliki oleh Yayasan Yatim Mandiri.

Untuk berpartisipasi dalam wakaf pada Yayasan Yatim Mandiri, masyarakat dapat menyalurkan minimal Rp. 100.000,-. Yayasan Yatim Mandiri Makassar juga memberikan sertifikat wakaf uang kepada wakif pada batasan tertentu dari jumlah uang yang diwakafkan setelah wakif mengutarakan niatnya dan menyerahkan sejumlah uang yang dimaksud.

Pendanaan adalah upaya yang dilakukan untuk mendapatkan dana dari sasaran wakif. Dalam mengumpulkan dana, setiap lembaga memiliki cara yang berbeda-beda. Cara yang dilakukan Yatim Mandiri adalah dengan menunggu wakif datang secara langsung dan dengan datang secara langsung kepada calon wakif. Hal ini tentunya merupakan tindak lanjut dari adanya sosialisasi yang dilakukan Yatim Mandiri. Dalam sosialisasinya, Yatim Mandiri melakukan promosi melalui berbagai media baik media cetak maupun elektronik. Sumber dana wakaf pada Yatim Mandiri berasal dari para donatur baik donatur tetap maupun donatur tidak tetap. 
Dalam penghimpunan wakaf uang pada yayasan yatim mandiri, strategi fundraising yang digunakan oleh fundreiser (zisco) yayasan yatim mandiri meliputi, direc yaitu strategi penghimpunan dengan cara pengambilan donasi secara rutin pada donatur aktif (setor jemput), yayasan yatim mandiri juga menggunakan strategi indirec fundraising dengan metode above the line dengan menggunakan media cetak (majalah)

Pendistribusian wakaf serta pemanfaatannya melalui beberapa langkah yang teliti. Pertama, riset internal dilakukan oleh nazhir Yatim Mandiri bersama tim lapangannya atau biasa disebut dengan zisco. Kedua, berdasarkan riset dan pengajuan dari pada wakif, Yayasan Yatim Mandiri kemudian mendata calon penerima dan lokasinya. Ketiga, setelah pendataan tim nazhir Yayasan Yatim Mandiri kemudian terjun langsung kelapangan untuk melihat akurasi riset dan pengajuan dari masyarakat. Sehingga dengan langsung survey ke lokasi, kekeliruan dan kesalahan distribusi dapat diminimalisir bahkan dihilangkan. Keempat, setelah survey dan dinilai cocok, maka eksekusi pun dilakukan, yang diikuti pencarian dana wakaf.

Yayasan Yatim Mandiri Makassar sangat membutuhkan dukungan baik dari luar maupun dari dalam lembaga. Dukungan dari dalam berupa pengurus pengurus yang amanah dan bekerja ulet dalam mengelola wakaf. Selain menggandeng puluhan partner lapangan. Para partner lapangan dapat diibaratkan tangan kanan yatim mandiri makassar. Mereka telah memberikan bantuan yang sangat besar bagi keberhasilan program - program yatim mandiri. Mereka berusaha semaksimal mungkin menyalurkan wakaf - wakaf ke daerah - daerah yang membutuhkan.

\section{KESIMPULAN}

Yayasan Yatim Mandiri Makassar memliki dua program, diantaranya ialah wakaf pembangunan dan wakaf al quran. Yayasan Yatim Mandiri Makassar juga memberikan sertifikat wakaf uang kepada wakif pada batasan tertentu dari jumlah uang yang diwakafkan setelah wakif mengutarakan niatnya dan menyerahkan 
sejumlah uang yang dimaksud. Dalam penghimpunan wakaf uang pada yayasan yatim mandiri, strategi fundraising yang digunakan oleh fundreiser (zisco) yayasan yatim mandiri meliputi, direc dan strategi indirec fundraising dengan metode above the line. Pendistribusian wakaf serta pemanfaatannya melalui beberapa langkah yang teliti. 


\section{DAFTAR PUSTAKA}

Atabik, Ahmad, 'Manajemen Pengelolaan Wakaf Tunai Di Indonesia', Ziswaf, 1.1 (2014), 82-107

Aziz, Muhammad, 'Peran Badan Wakaf Indonesia (BWI) Dalam Mengembangkan Prospek Wakaf Uang Di Indonesia', JES (Jurnal Ekonomi Syariah), 2.1 (2017), 35-54 <https://doi.org/10.30736/jesa.v2i1.14>

Muhammad, Tho'in, and Iin Emy Prastiwi, 'Wakaf Tunai Perspektif Syariah', Jurnal Ilmiah Ekonomi Islam, 01.01 (2015), 61-74

Sirajuddin Sirajuddin, and Asrum Yolleng, 'PEMBERDAYAAN TANAH WAKAF SEBAGAI POTENSI EKONOMI UMAT DI MASJID ALMARKAZ Al-ISLAMI MAKASSAR', LAA MAISYIR : Jurnal Ekonomi Islam, 5.1 (2018), 80-106 <https://doi.org/10.24252/laamaisyir.v5i1a4>

Suganda, A. D. (2014). Konsep Wakaf Tunai. ISLAMICONOMIC: Jurnal Ekonomi Islam, 5(2).

Sudrajat, S. S. (2017). Efektivitas pendayagunaan dana wakaf terhadap programprogram Badan Wakaf Al-Qur'an Jakarta Tahun 2016 (Bachelor's thesis, UIN Syarif Hidayatullah Jakarta: Fakultas Dakwah dan Ilmu Komunikasi, 2017).

Tho’in, M., \& Prastiwi, I. E. (2015). Wakaf Tunai Perspektif Syariah. Jurnal Ilmiah Ekonomi Islam, 1(02).

Undang-Undang, R. I. (2005). No. 41 Tahun 2004 tentang Wakaf. Departemen Agama RI, Dirjen Bimas Islam dan Penyelenggaraan Haji.

https://www.yatimmandiri.org/welcome/profil

https://www.jogpaper.com/index.php/disertasi/202-indonesia-masih-kesulitanterapkan-wakaf-tunai 